\title{
Analytical Expressions of Concentrations of Substrate and Hydroquinone in an Amperometric Glucose Biosensor
}

\author{
M. Uma Maheswari and L. Rajendran \\ Department of Mathematics, The Madura College, Madurai, Tamil Nadu 625011, India \\ Correspondence should be addressed to L. Rajendran; raj_sms@rediffmail.com
}

Received 27 September 2012; Accepted 5 November 2012

Academic Editors: T. Buhse and C. A. Hacker

Copyright ( 2013 M. Uma Maheswari and L. Rajendran. This is an open access article distributed under the Creative Commons Attribution License, which permits unrestricted use, distribution, and reproduction in any medium, provided the original work is properly cited.

\begin{abstract}
The theoretical model for an amperometric glucose biosensor is discussed. In this model glucose oxidase enzyme is immobilized in conducting polypyrrole. This model contains a nonlinear term related to enzyme reaction kinetics. He's homotopy perturbation method is used to find the approximate analytical solutions of coupled non-linear reaction diffusion equations. A closed-form expression of substrate and mediator concentration under non-steady-state conditions is obtained. A comparison of the analytical approximation and numerical simulation is also presented. An agreement between analytical expressions and numerical results is observed.
\end{abstract}

\section{Introduction}

Since the second half of the last century, numerous efforts have been devoted to the development of insoluble immobilized enzymes for a variety of applications [1]. These applications can clearly benefit from use of the immobilized enzymes rather than the soluble counterparts, for instance as reusable heterogeneous biocatalysts, with the aim of reducing production costs by efficient recycling and control of the process [2], as stable and reusable devices for analytical and medical applications [3-9], as selective adsorbents for purification of proteins and enzymes [10], as fundamental tools for solid-phase protein chemistry [11, 12], and as effective microdevices for controlled release of protein drugs [13].

Immobilized enzymes are becoming increasingly popular as reusable, selective analytical chemical reagents in solidphase flow-through reactors, as membranes in sensors, and as films in dry reagent kits. The attractions of immobilized enzymes from an analytical standpoint are primarily their reusability, and hence cost saving, and the greater efficiency and control of their catalytic activity [14] (e.g., potentially longer half-lives, predictable decay rates and more efficient multistep reactions).
The immobilization of enzymes in conducting polymer [15] during electro-polymerization step has proved to be well suited to the preparation of biosensors [16-19]. This method is simple and easy to control. Another important advantage of this immobilization technique is the possibility of entrapping the mediator in the polymer as a dopant anion [20-23] or by covalent fixation on the pyrrole monomer [24]. Bartlett and Whitaker [25] have already presented a theoretical model for an amperometric polypyrrole + glucose oxidase (PPY + GOD) electrode. In their model PPY was considered as an insulating polymer, and the reduced mediator $\mathrm{H}_{2} \mathrm{O}_{2}$ was oxidized at the metallic surface after diffusion in the polymer. Marchesiello and Geniès [26] obtained the analytical expressions of concentrations of substrate and benzoquinone for low substrate and high benzoquinone concentration compared with respective Michaelis constants.

To my knowledge no rigorous analytical expressions of concentrations of substrate and mediator of ampereometric glucose under non-steady-state conditions for all values parameters $\alpha, \alpha^{\prime}$ and $M$ have been reported. These parameters are defined in (6). The purpose of this communication is to derive approximate analytical expressions for the 


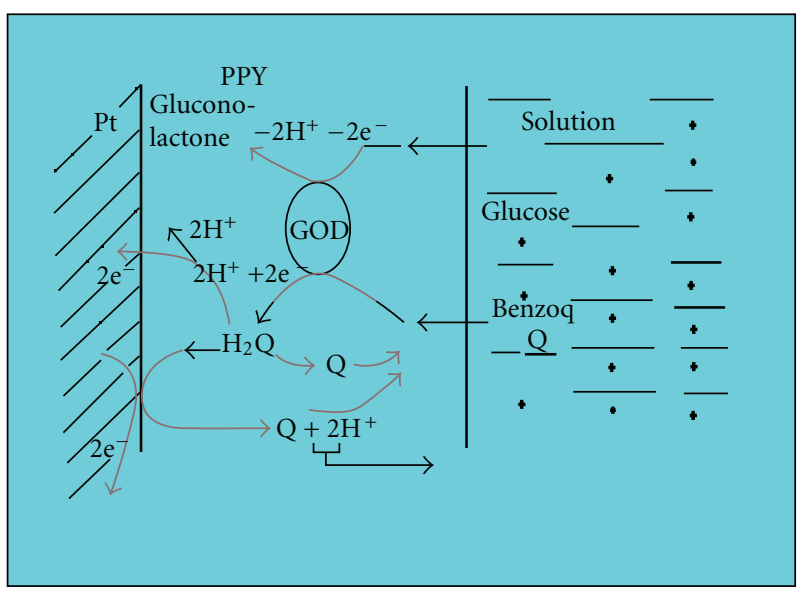

FIGURE 1: Schematic diagram of the electrocatalytic oxidation of glucose at a GOD + PPY electrode in the presence of benzoquinone (Q).

non-steady-state concentrations and current using Homotopy perturbation method.

\section{Mathematical Formulation and Analysis of the Problems}

2.1. Mathematical Formulation. Building upon earlier work, Marchesiello and Geniès [26] presented a concise discussion and derivation of mass transport nonlinear equations in glucose biosensor, which is summarized briefly below. Figure 1 is a schematic representation of the PPY + GOD electrode working as a glucose sensor. The different steps which lead to the electrocatalytic current are as follows. (i) Glucose and benzoquinone diffusion from bulk of the solution to the electrode, (ii) glucose and benzoquinone diffusion into the conducting polymer, and (iii) the enzymatic reaction between glucose and benzoquinone:

$$
\begin{aligned}
& \text { Glucose }+ \text { GOD }(\mathrm{FAD}) \\
& \quad \longrightarrow \text { GOD }\left(\mathrm{FADH}_{2}\right)+\text { gluconolactone } \\
& \mathrm{Q}+\mathrm{GOD}\left(\mathrm{FADH}_{2}\right) \longrightarrow \mathrm{GOD}(\mathrm{FAD})+\mathrm{H}_{2} \mathrm{Q}
\end{aligned}
$$

(iv) The oxidation of hydroquinone: $\mathrm{H}_{2} \mathrm{Q} \rightarrow \mathrm{Q}+2 \mathrm{H}^{+}+2 \mathrm{e}^{-}$.

As shown in Figure 1, this reaction occurs on the surface of the platinum electrode after diffusion in the polymer and in the conducting polymer itself. The rate of the enzymatic reaction between glucose and benzoquinone follows a pingpong type mechanism [27] $v=k_{\text {cat }}[\mathrm{E}] /\left\lfloor 1+K_{\mathrm{Q}} /[\mathrm{Q}]+\right.$ $\left.K_{\mathrm{S}} /[\mathrm{S}]\right\rfloor$ where $k_{\text {cat }} / \mathrm{s}^{-1}$ is the turnover number for GOD, $K_{\mathrm{S}}$ and $K_{\mathrm{Q}}$ are the Michaelis constants for glucose and benzoquinone, respectively, and [E], [Q], and [S] are the enzyme, benzoquinone, and glucose concentrations in the film. The third term is the $\mathrm{H}_{2} \mathrm{Q}$ oxidation term. The rate of the electrochemical reaction in the conducting polymer can be written as $v=K \Sigma\left[\mathrm{H}_{2} \mathrm{Q}\right]$, where $K / \mathrm{ms}^{-1}$ is the chargetransfer constant for the oxidation of $\mathrm{H}_{2} \mathrm{Q}$ in the conducting polymer. It depends on the electrode potential. $\Sigma$ is the PPY specific surface and it was estimated to be in the range $5-50 \mathrm{~m}^{2} \mathrm{~m}^{-3}$ for a PPY electrode deposited film [28]. The differential equations describing the concentrations of $S$ and $\mathrm{H}_{2} \mathrm{Q}$ at steady state are as follows [26]:

$$
\begin{gathered}
D_{\mathrm{S}} \frac{d^{2}[\mathrm{~S}]}{d x^{2}}-\frac{k_{\text {cat }}[\mathrm{E}]}{1+K_{\mathrm{Q}} /[\mathrm{Q}]+K_{\mathrm{S}} /[\mathrm{S}]}=0 \\
D_{\mathrm{H}_{2} \mathrm{Q}} \frac{d^{2}\left[\mathrm{H}_{2} \mathrm{Q}\right]}{d x^{2}}+\frac{k_{\mathrm{cat}}[\mathrm{E}]}{1+K_{\mathrm{Q}} /[\mathrm{Q}]+K_{\mathrm{S}} /[\mathrm{S}]}=K \Sigma\left[\mathrm{H}_{2} \mathrm{Q}\right] .
\end{gathered}
$$

These nonlinear reaction/diffusion equations are solved for the following boundary conditions. The boundary conditions are as follows [27]:

$$
\begin{aligned}
& {[\mathrm{S}]=[\mathrm{S}]_{0}, \quad\left[\mathrm{H}_{2} \mathrm{Q}\right]=0,} \\
& \text { at } x=L(\text { polymer/solution interface }), \\
& \frac{d[\mathrm{~S}]}{d x}=0, \quad\left[\mathrm{H}_{2} \mathrm{Q}\right]=0,
\end{aligned}
$$$$
\text { at } x=0 \text { (platinum/polymer interface). }
$$

The total electrocatalytic current $I_{T}$ is the sum of two currents. The current

$$
I_{\mathrm{S}}=2 \mathrm{FAD}_{\mathrm{H}_{2} \mathrm{Q}}\left(\frac{d\left[\mathrm{H}_{2} \mathrm{Q}\right]}{d x}\right)_{x=0} .
$$

For $\mathrm{H}_{2} \mathrm{Q}$ oxidation on the platinum electrode, and

$$
I_{P}=\int_{0}^{L} d I=\int_{0}^{L} 2 \mathrm{FAK} \Sigma\left[\mathrm{H}_{2} \mathrm{Q}\right] d x,
$$

where $L$ is the film thickness of the reaction layer. We assume that there is no concentration polarization of $\mathrm{S}$ and $\mathrm{H}_{2} \mathrm{Q}$ in the solution and that the partition coefficients are equal to unity. $\left[\mathrm{S}_{0}\right]$ is the concentration of glucose in the bulk of the solution.

2.2. Normalized Form. By introducing the following set of nondimensional variables,

$$
\begin{gathered}
X=x / L, \quad U=[\mathrm{S}] /[\mathrm{S}]_{0}, \quad V=\left[\mathrm{H}_{2} \mathrm{Q}\right] /[\mathrm{S}]_{0}, \\
\alpha=L / \Lambda, \quad \alpha^{\prime}=L / \Lambda^{\prime}, \\
\Lambda=\left(\frac{D_{\mathrm{S}} K_{\mathrm{S}}}{K_{\text {cat }}[\mathrm{E}]}\right)^{1 / 2}, \quad \Lambda^{\prime}=\left(\frac{D_{\mathrm{H}_{2} \mathrm{Q}}}{K \Sigma}\right)^{1 / 2}, \\
M=\frac{[\mathrm{S}]_{0}}{K_{\mathrm{S}}}+\frac{[\mathrm{S}]_{0} K_{\mathrm{Q}}}{K_{\mathrm{S}}[\mathrm{Q}]} .
\end{gathered}
$$

The dimensionless parameters $\alpha$ compares the enzymatic reaction rate with the substrate diffusion in the polymer. The dimensionless parameter $\alpha^{\prime}$ compares the $\mathrm{H}_{2} \mathrm{Q}$ oxidation rate in the conducting polymer with $\mathrm{H}_{2} \mathrm{Q}$ diffusion in the polymer. For electrochemically inert polymer, $\alpha^{\prime}$ has low value and for electrochemically active polymer, $\alpha^{\prime}$ has high value. The parameter $M$ is a dimensionless constant. 


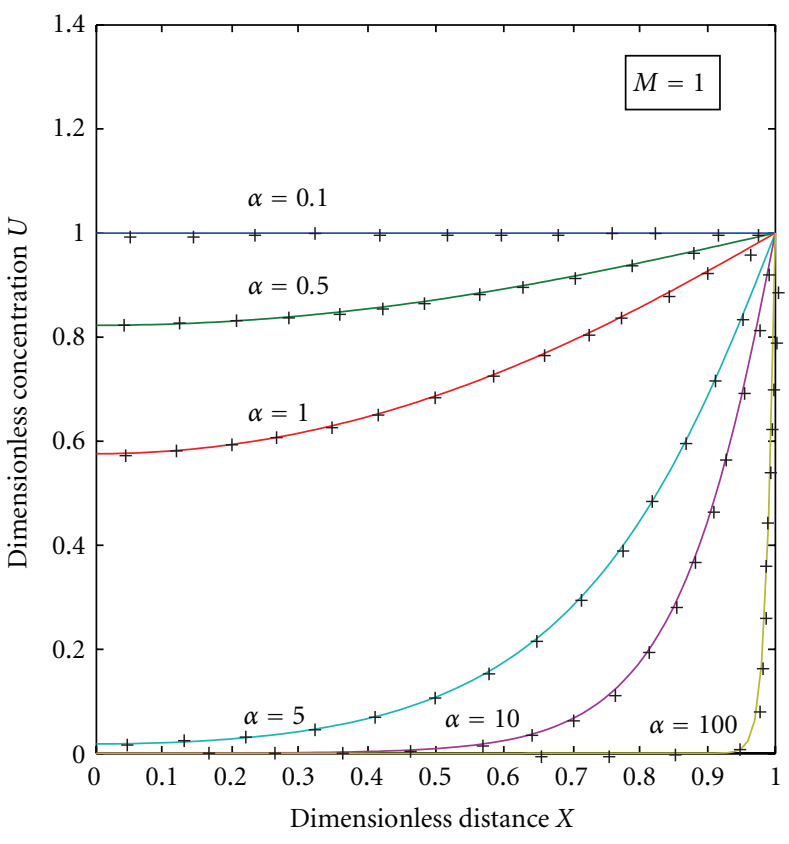

(a)

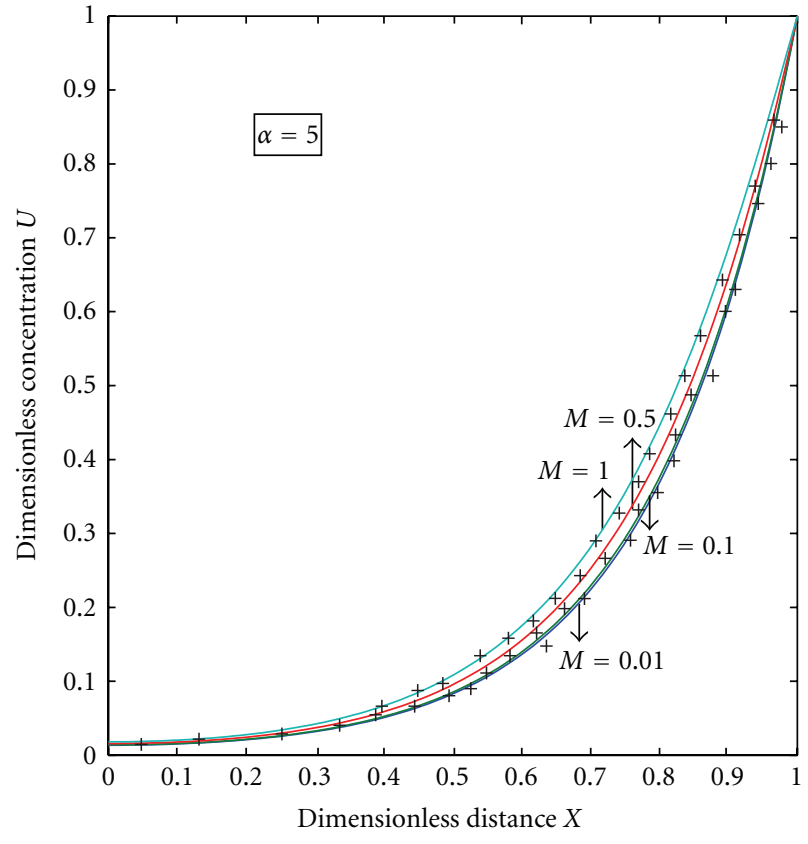

(b)

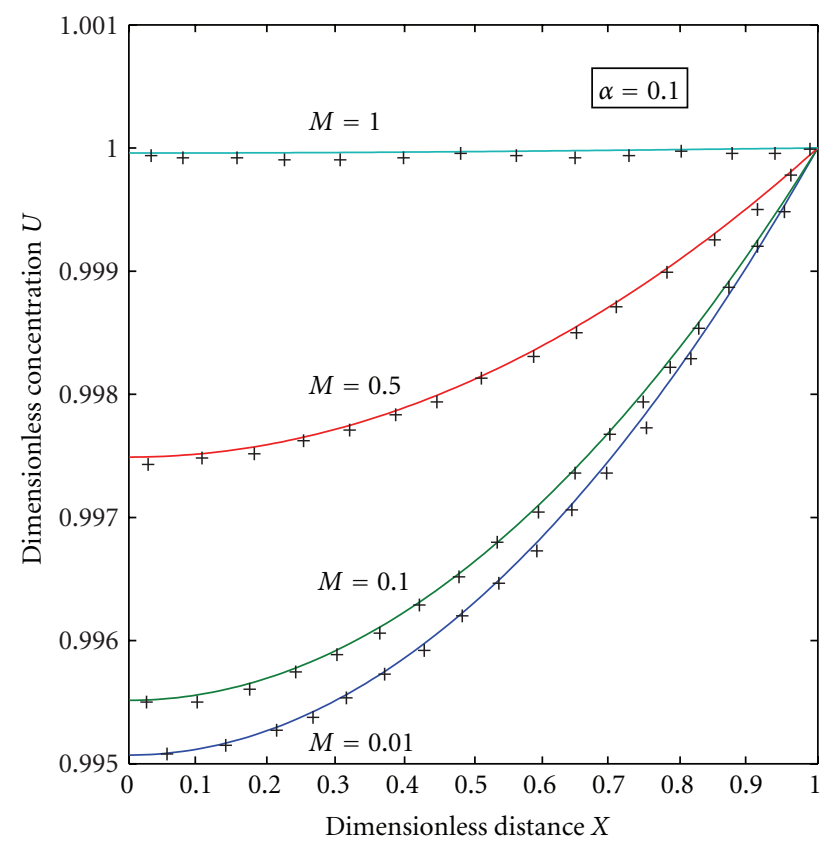

(c)

FIgURE 2: Profile of the normalized concentrations of the glucose. The concentrations were computed for various values of $\alpha$ and $M$. The curves are plotted using (10).

The coupled reaction/diffusion equations (2) take the following normalized form:

$$
\begin{gathered}
\frac{d^{2} U}{d X^{2}}-\frac{\alpha^{2} U}{M U+1}=0, \\
\frac{d^{2} V}{d X^{2}}+\frac{\alpha^{2} U}{M U+1}=\alpha^{\prime 2} V
\end{gathered}
$$

where $U$ and $V$ are the dimensionless concentration of $S$ and $\mathrm{H}_{2} \mathrm{Q}$.

The transformed boundary conditions are

$$
\begin{gathered}
\frac{d U}{d X}=0, \quad V=0, \quad \text { when } X=0, \\
U=1, \quad V=0, \quad \text { when } X=1 .
\end{gathered}
$$


The dimensionless form of the current is given by

$$
\begin{gathered}
\psi_{\mathrm{S}}=\frac{I_{\mathrm{S}}}{2 \mathrm{FAD}_{\mathrm{H}_{2} \mathrm{Q}}}=\left[\frac{d[V]}{d X}\right]_{X=0}, \\
\psi_{\mathrm{P}}=\frac{I_{\mathrm{P}}}{2 \mathrm{FAK} \Sigma}=\int_{0}^{1} V d X .
\end{gathered}
$$

2.3. Analytical Expressions of Concentrations of Substrate and the Mediator under Steady-State Condition. In recent days, Homotopy perturbation method (HPM) is often employed to solve several analytical problems. In addition, several groups demonstrated the efficiency and suitability of the HPM for solving nonlinear equations and other electrochemical problems [29-32]. Mousa and Ragab [33] used HPM to solve the Lighthill equation, the Duffing equation [34], and the Blasius equation [35]. HPM has also been used to solve nonlinear boundary value problems [33], integral equation [3638], Emden-Flower type equations [39], and several other problems. Detailed derivation of the concentrations using Homotopy perturbation method is described in Appendix 5. As a result, we can obtain the dimensionless concentrations of substrate and mediator as follows:

$$
\begin{aligned}
& U(X, \alpha)= \frac{\cosh (\alpha X)}{\cosh (\alpha)}+\frac{M \cosh (\alpha X)[\cosh (2 \alpha)-3]}{6 \cosh ^{3}(\alpha)} \\
&-\frac{M[\cosh (2 \alpha X)-3]}{6 \cosh ^{2}(\alpha)}, \\
& V(X, \alpha, M)=\frac{\alpha^{2}}{\alpha^{\prime 2}(M+1)}\left[1-\frac{e^{\alpha^{\prime} X}+e^{\alpha^{\prime}(1-X)}}{\left(e^{\alpha^{\prime}}+1\right)}\right] .
\end{aligned}
$$

The dimensionless current $\psi_{\mathrm{S}}$ and $\psi_{\mathrm{P}}$ are obtained using (9) and (11):

$$
\begin{aligned}
\psi_{\mathrm{S}}\left(\alpha, \alpha^{\prime}, M\right) & =\frac{\alpha^{2}\left(e^{\alpha^{\prime}}-1\right)}{\alpha^{\prime}(M+1)\left(e^{\alpha^{\prime}}+1\right)}, \\
\psi_{\mathrm{P}}\left(\alpha, \alpha^{\prime}, M\right)= & \frac{\alpha^{2}\left(\alpha^{\prime} e^{\alpha^{\prime}}-e^{\alpha^{\prime}}+\alpha^{\prime}+1\right)}{\alpha^{\prime 3}(M+1)\left(e^{\alpha^{\prime}}+1\right)} \\
& -\frac{\alpha^{2}\left(e^{\alpha^{\prime}}-1\right)}{\alpha^{\prime 3}(M+1)\left(e^{\alpha^{\prime}}+1\right)} .
\end{aligned}
$$

The electrocatalytic current $\psi_{T}$ is the sum of two currents $\psi_{\mathrm{S}}$ and $\psi_{\mathrm{P}}$

$$
\begin{aligned}
\psi_{T}\left(\alpha, \alpha^{\prime}, M\right)= & \frac{\alpha^{2}\left(e^{\alpha^{\prime}}-1\right)}{\alpha^{\prime 3}(M+1)\left(e^{\alpha^{\prime}}+1\right)} \\
& \times\left[e^{\alpha^{\prime}}\left(\alpha^{\prime}-1\right)+\alpha^{\prime}\left(\alpha^{\prime}+1\right)\right] .
\end{aligned}
$$

2.4. First-Order Catalytic Kinetics. In this case, $M U<1$ or $1+$ $K_{\mathrm{Q}} /[\mathrm{Q}] \ll K_{\mathrm{S}} /[\mathrm{S}]$. Now (7) reduces to the following forms:

$$
\begin{gathered}
\frac{d^{2} U}{d X^{2}}-U \alpha^{2}=0, \\
\frac{d^{2} V}{d X^{2}}+U \alpha^{2}=\alpha^{\prime 2} V
\end{gathered}
$$

The solutions of (15) are given as follows:

$$
U(X, \alpha)=\frac{\cosh (\alpha X)}{\cosh (\alpha)},
$$

$$
\begin{gathered}
V\left(X, \alpha, \alpha^{\prime}\right) \\
=\frac{\alpha^{2}}{\left(\alpha^{2}-\alpha \prime^{2}\right)}\left[\frac{e^{\alpha^{\prime} X}}{\cosh (\alpha)}-\frac{\cosh (\alpha X)}{\cosh (\alpha)}\right. \\
\left.-\frac{\sinh \left(\alpha^{\prime} X\right)}{\sinh \left(\alpha^{\prime}\right)}\left(\frac{e^{\alpha^{\prime}}}{\cosh (\alpha)}-1\right)\right], \\
\psi_{\mathrm{S}}\left(\alpha, \alpha^{\prime}\right)=\frac{\alpha^{\prime} \alpha^{2}}{\left(\alpha^{2}-\alpha^{\prime 2}\right)} \\
\times\left[\frac{1}{\cosh (\alpha)}-\frac{1}{\sinh \left(\alpha^{\prime}\right)}\left(\frac{e^{\alpha^{\prime}}}{\cosh (\alpha)}-1\right)\right],
\end{gathered}
$$

$$
\begin{aligned}
\psi_{\mathrm{P}}\left(\alpha, \alpha^{\prime}\right)= & \frac{\alpha^{2}}{\left(\alpha^{2}-\alpha^{\prime 2}\right)} \\
\times & {\left[\left(\frac{1}{\cosh (\alpha)}\right)\right.} \\
& \left.-\frac{1}{2 \sinh \left(\alpha^{\prime}\right)}\left(\frac{e^{\alpha^{\prime}}}{\cosh (\alpha)}-1\right)\right) \\
& \times\left(\frac{1}{\alpha^{\prime}}\left(e^{\alpha^{\prime}}-1\right)\right) \\
& +\frac{\left(e^{-\alpha^{\prime}}-1\right)}{2 \alpha^{\prime} \sinh \left(\alpha^{\prime}\right)}\left(\frac{e^{\alpha^{\prime}}}{\cosh (\alpha)}-1\right) \\
& \left.-\left(\frac{\sinh (\alpha)}{\alpha^{2} \cosh (\alpha)}\right)\right] \\
& \psi_{T}=\psi_{S}+\psi_{P} .
\end{aligned}
$$

2.5. Zero-Order Catalytic Kinetics. In this case, $M U>1$ or $1+K_{\mathrm{Q}} /[\mathrm{Q}] \gg K_{\mathrm{S}} /[\mathrm{S}]$. Now $(7)$ reduce to the following forms:

$$
\begin{gathered}
\frac{d^{2} U}{d X^{2}}-\frac{\alpha^{2}}{M}=0, \\
\frac{d^{2} V}{d X^{2}}+\frac{\alpha^{2}}{M}=\alpha \prime^{2} V .
\end{gathered}
$$




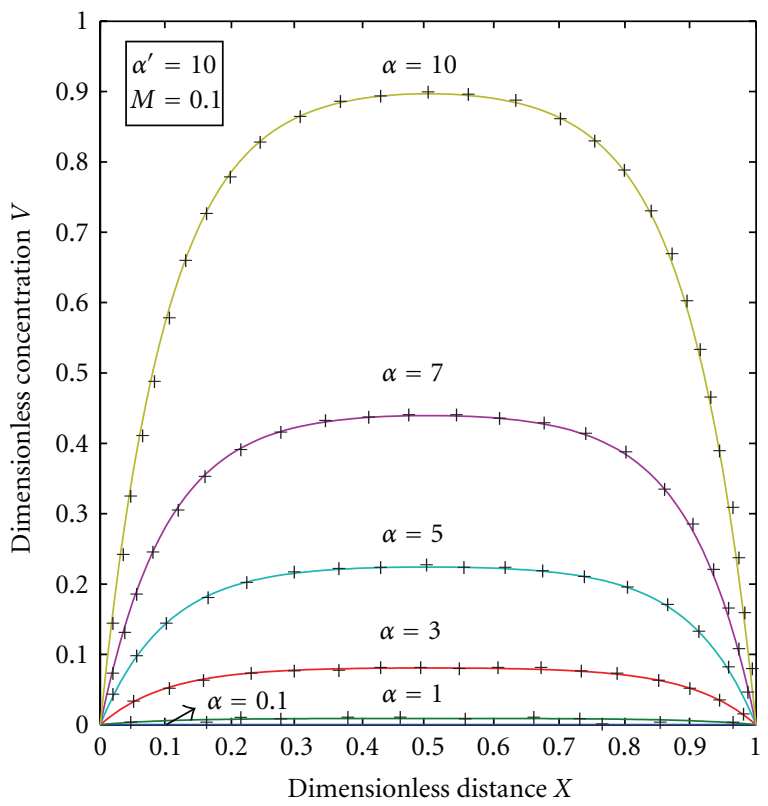

(a)

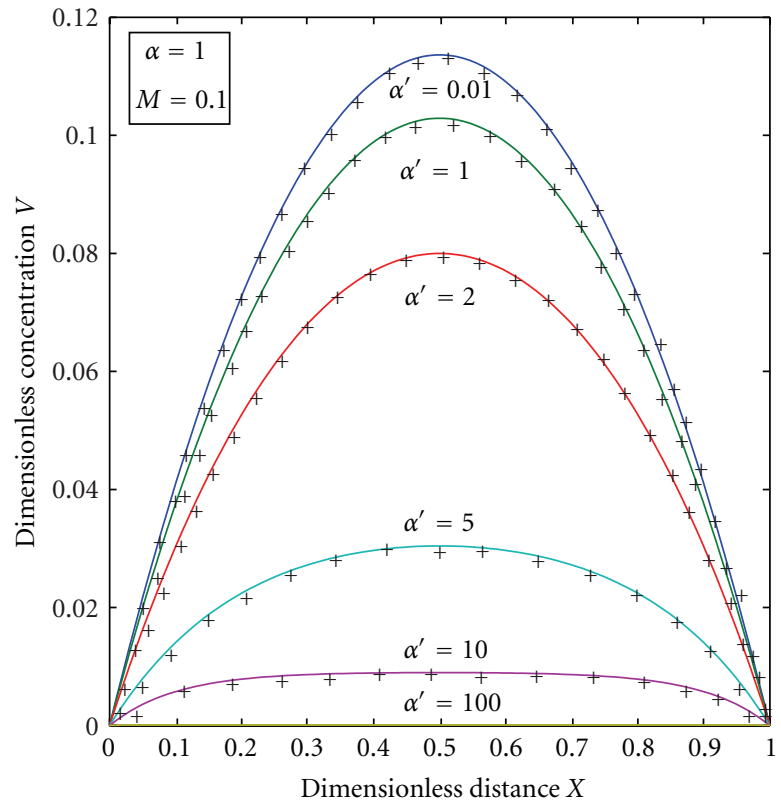

(b)

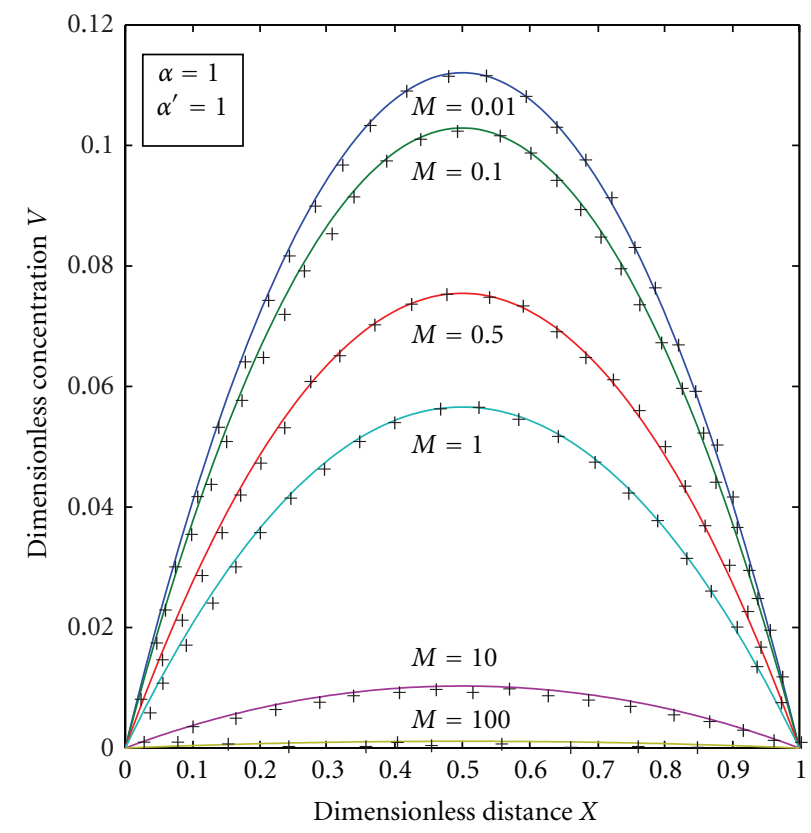

(c)

FIGURE 3: Profile of the normalized concentration of the mediator. The concentrations were computed for various values of $\alpha, \alpha^{\prime}$, and $M$. The curves are plotted using (11).

The solution of (21) is given as follows:

$$
\begin{gathered}
U(X, \alpha, M)=1-\frac{\alpha^{2}}{2 M}\left(1+X^{2}\right), \\
V\left(X, \alpha, \alpha^{\prime}, M\right)=\frac{\alpha^{2}}{M \alpha^{\prime 2}}\left[1-\frac{M e^{\alpha^{\prime} X}+e^{\alpha^{\prime}(1-X)}}{M\left(e^{\alpha^{\prime}}+1\right)}\right] .
\end{gathered}
$$

The current is given by

$$
\psi_{\mathrm{S}}\left(\alpha, \alpha^{\prime}, M\right)=\frac{\alpha^{2}}{M \alpha^{\prime 2}\left(e^{\alpha^{\prime}}+1\right)}\left(\frac{e^{\alpha^{\prime}}}{\left(e^{\alpha^{\prime}}+1\right)}-\alpha^{\prime}\right),
$$

$$
\begin{gathered}
\psi_{\mathrm{P}}\left(\alpha, \alpha^{\prime}, M\right)=-\frac{2 \alpha^{2}\left(1-e^{\alpha^{\prime}}\right)}{M \alpha^{\prime 3}\left(1+e^{\alpha^{\prime}}\right)}, \\
\psi_{\mathrm{T}}=\psi_{\mathrm{S}}+\psi_{\mathrm{P}} .
\end{gathered}
$$

\section{Numerical Simulation}

The nonlinear differential equations (7) are also solved numerically. The function pdepe in Matlab/Scilab software 

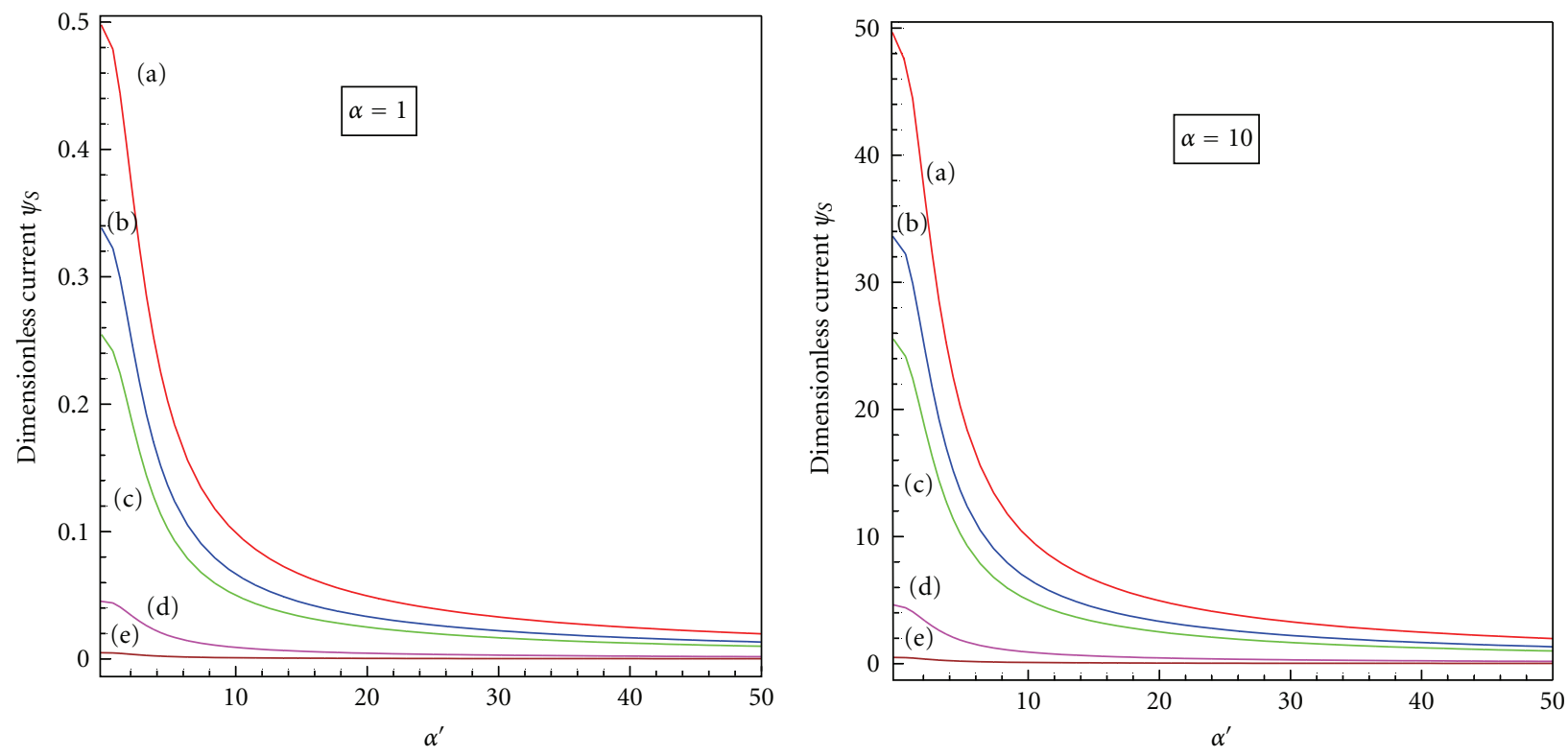

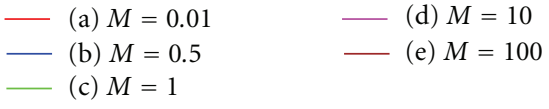

(a)

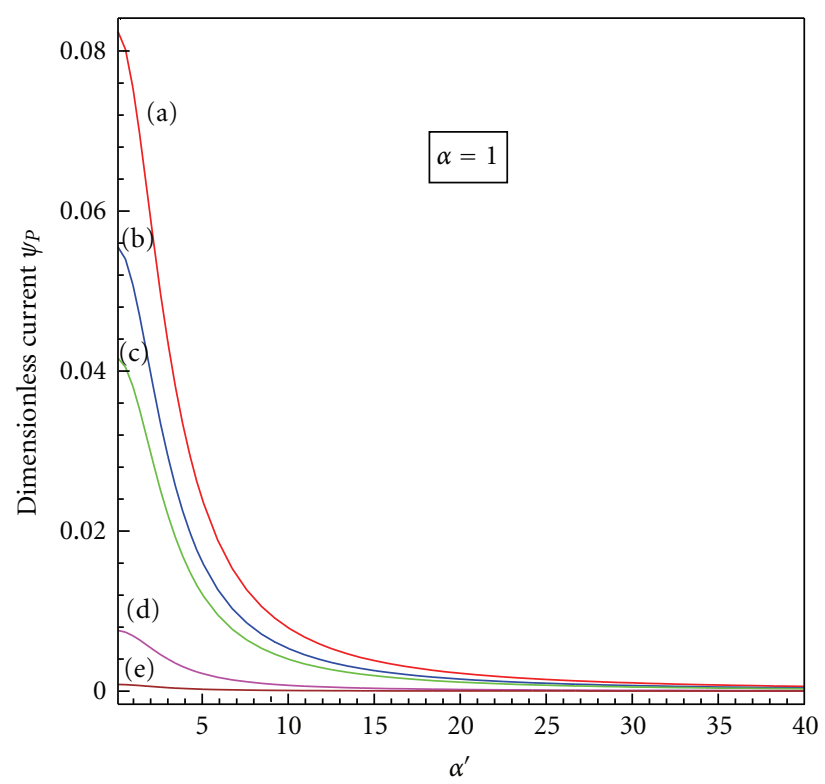

(a) $M=0.01$

(b) $M=0.5$

(c) $M=1$ (d) $M=10$ (e) $M=100$
(a) $M=0.01$
(b) $M=0.5$
(c) $M=1$

(

- (e) $M=100$

(b)

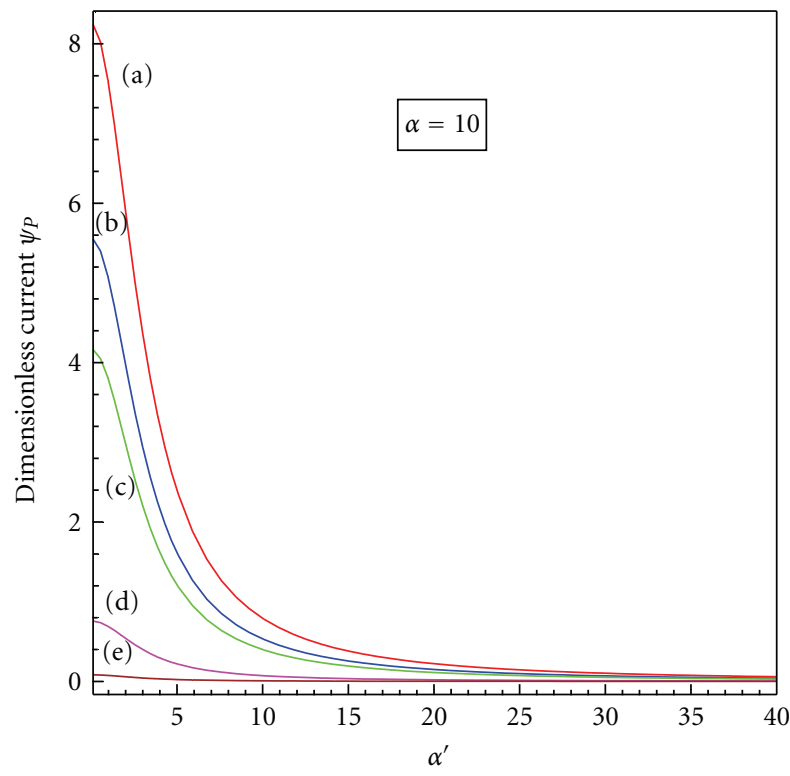

(a) $M=0.01$

(b) $M=0.5$

(c) $M=1$

(c)

(d)

Figure 4: Profile of the normalized current. The current curves were computed for various values of $\alpha, \alpha^{\prime}$, and $M$. The curves are plotted using (12) and (13).

is used to solve boundary value problems (BVPs) for partial differential equations. The numerical solution is compared with our analytical results. The Matlab/Scilab program is also given in Table 1. Upon comparison it is evident that both results gives satisfactory agreement.

\section{Discussion}

Figures 2(a)-2(c) represents the normalized non-steady state concentration of substrate $U$ versus dimensionless distance $X$, for different values of dimensionless reaction diffusion 


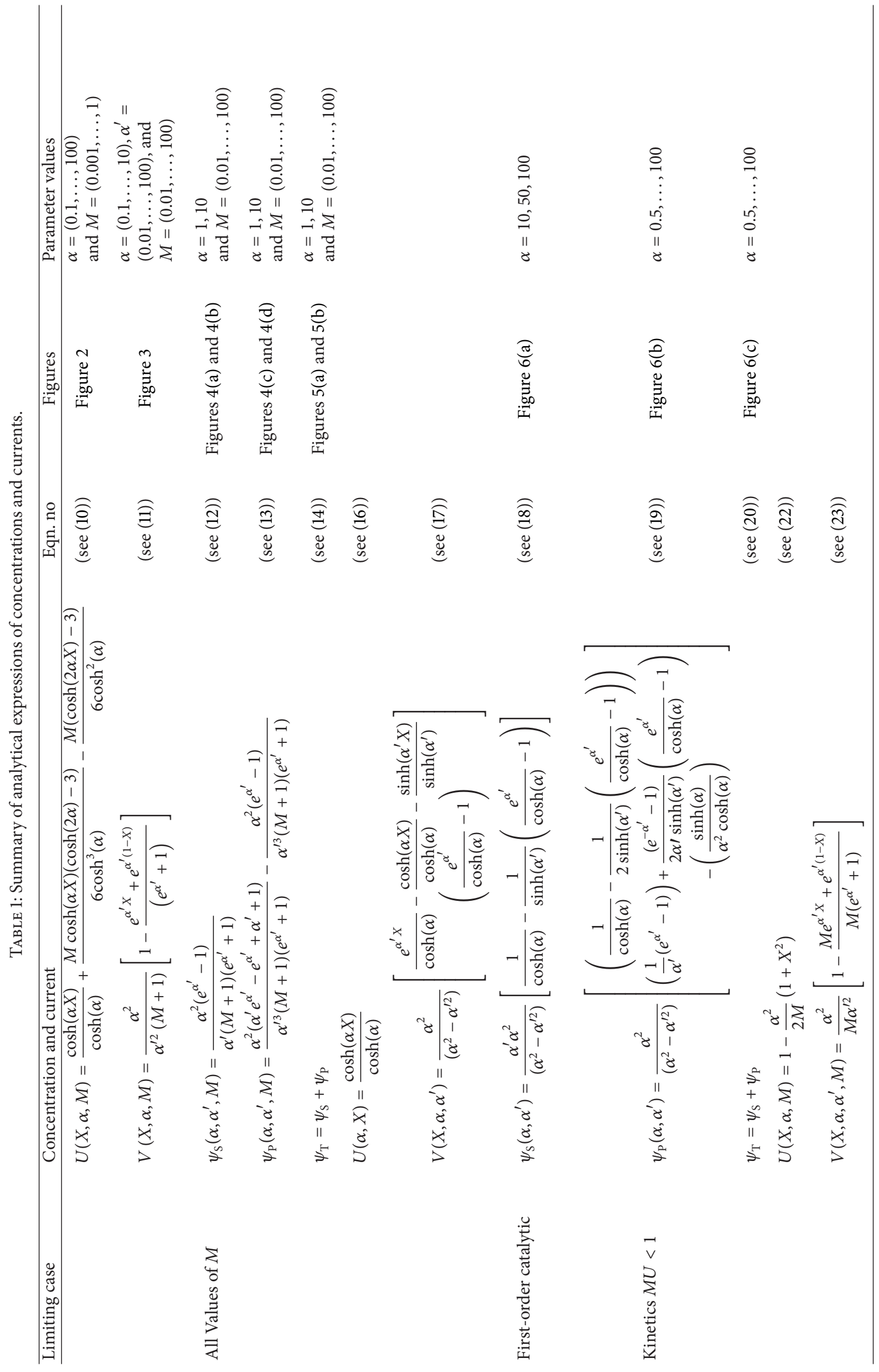




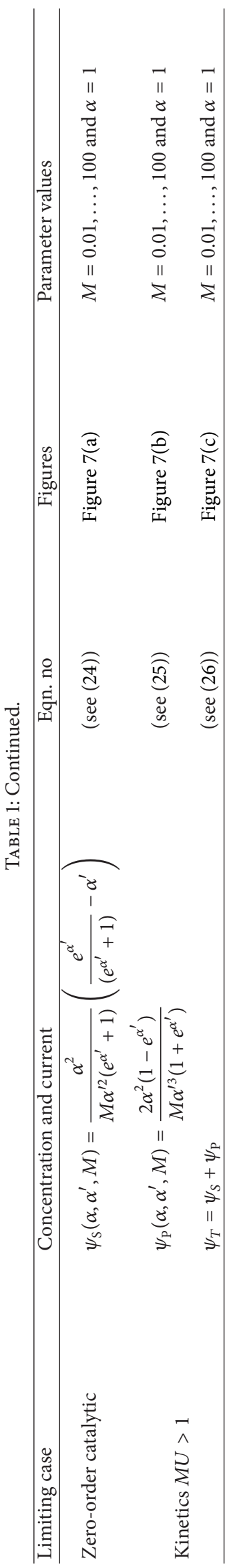




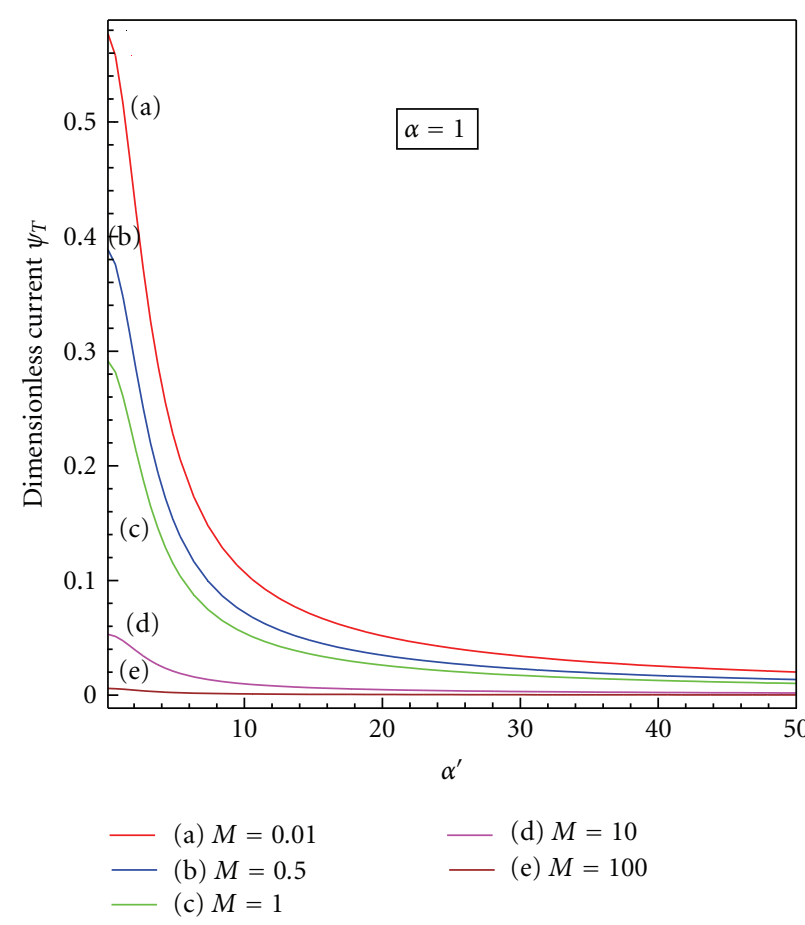

(a)

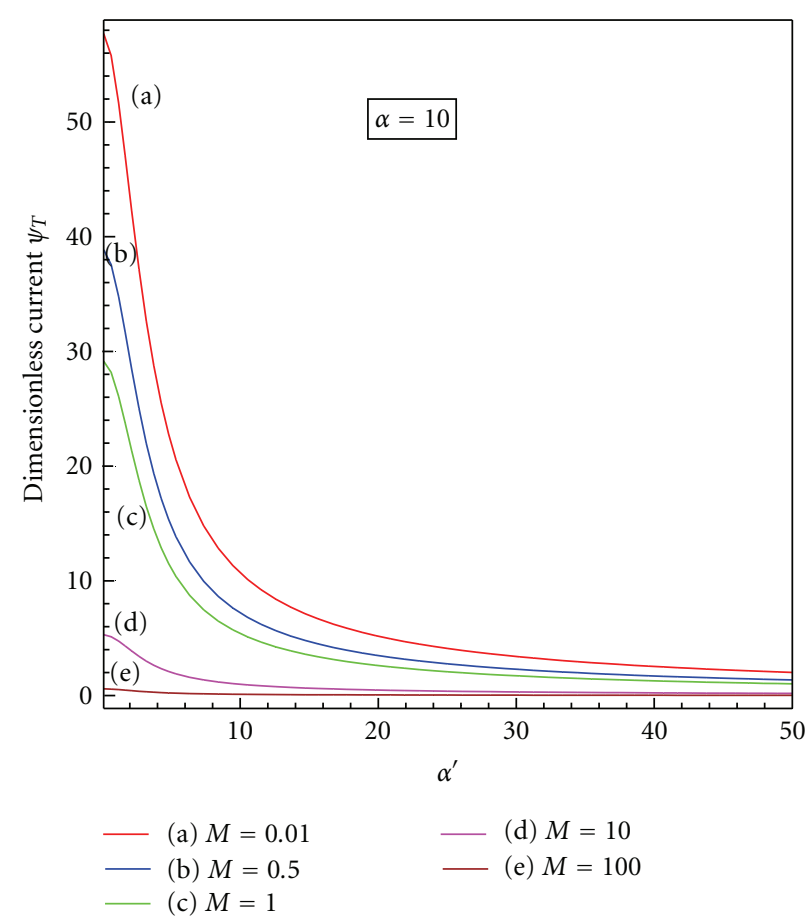

(b)

Figure 5: Profile of the normalized current. The current curves were computed for various values of $\alpha, \alpha^{\prime}$, and $M$. The curves are plotted using (14).

parameter $\alpha=0.1, \ldots, 100$ and $M=0.001, \ldots, 1$. From this figure, it is evident that the concentration of substrate increases when $\alpha$ decreases and $M$ increases. From this Figures $1(\mathrm{a})-1(\mathrm{c})$, it is evident that the value of concentration is uniform when $\alpha \geq 0.5$.

Figures 3(a)-3(c) shows the concentration of mediator $V$ versus dimensionless distance $X$, for various values of dimensionless diffusion parameter $\alpha(=0.1, \ldots, 10), \alpha^{\prime}(=$ $0.01, \ldots, 100)$ and $M(=0.01, \ldots, 100)$. From this figure, it is inferred that the value of the concentration of mediator decreases abruptly when $\alpha$ decreases and $M$ and $\alpha^{\prime}$ increases. Also the concentration of mediator reaches the maximum value at the middle of membrane $(x=0.5)$ for all values of $\alpha$, $\alpha^{\prime}$, and $M$.

The normalized steady state current $\psi_{\mathrm{S}}\left(\alpha, \alpha^{\prime}, M\right)$ and $\psi_{\mathrm{P}}\left(\alpha, \alpha^{\prime}, M\right)$ as the function of the dimensionless parameter $\alpha^{\prime}$ is given in Figures 4(a)-4(d). From this figures, it is obvious that the values of the current decreases slowly and reaches constant value when $\alpha^{\prime} \geq 40$. Also values of the current decreases when $M$ increases.

In Figures 5(a)-5(b), profile of the normalized current $\psi_{\mathrm{T}}$ is shown. The current were computed for various values of $\alpha, \alpha^{\prime}$, and $M$. The curves are plotted using (12). The value of the current increases when $\alpha$ increases. The normalized non-steady-state current for diverse values of dimensionless diffusion parameter $\alpha$ is plotted in Figures 6(a)-6(c).

\section{Conclusions}

The steady state nonlinear reaction/diffusion equations in an amperometric glucose sensor have been solved analytically.
An approximate analytical expression for the concentrations and current for an amperometric glucose sensor are obtained by using the Homotopy perturbation method. The primary result of this work is simple approximate calculation of concentration profiles and current for all values of fundamental parameters $\alpha$ and $\alpha^{\prime}$. The analytical results obtained can be used for the optimization of the design of glucose sensor.

\section{Appendix}

\section{Approximate Analytical Expression of the Normalized Concentration of Substrate and $\mathrm{H}_{2} \mathrm{Q}$}

Using Homotopy perturbation method, we construct a homotopy for (7) as follows:

$$
\begin{gathered}
(1-p)\left(\frac{d^{2} U}{d X^{2}}\right)+p\left[\frac{d^{2} U}{d X^{2}}-\frac{\alpha^{2} U}{M U+1}\right]=0, \\
(1-p)\left(\frac{d^{2} V}{d X^{2}}-\alpha^{\prime 2} V\right)+p\left[\frac{d^{2} V}{d X^{2}}-\alpha^{\prime 2} V+\frac{\alpha^{2} U}{M U+1}\right]=0 .
\end{gathered}
$$

The approximate solution of (A.1) is given by

$$
U=U_{0}+p U_{1}+p^{2} U_{2}+p^{3} U_{3}+\cdots .
$$




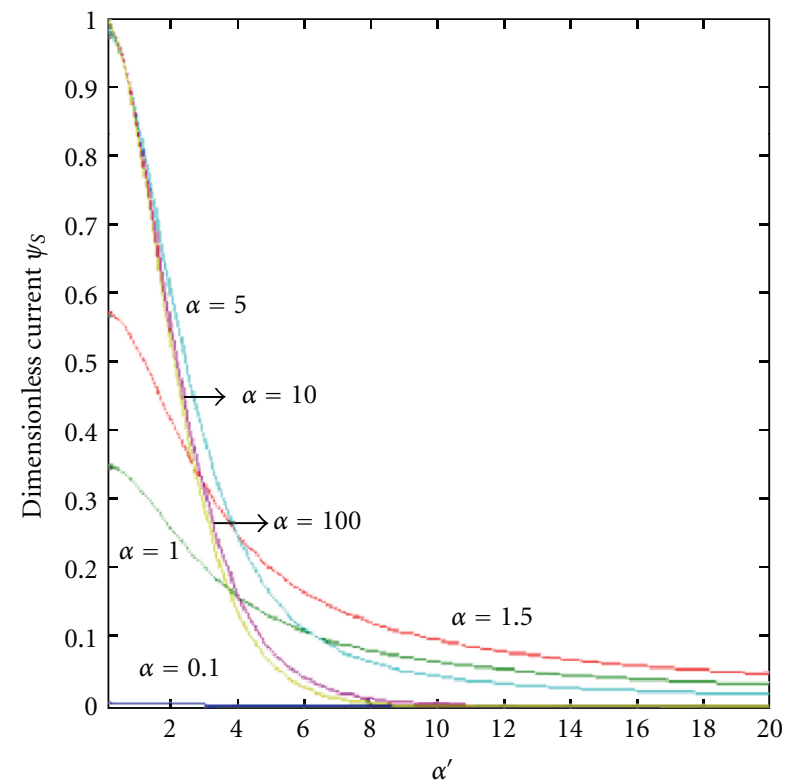

(a)

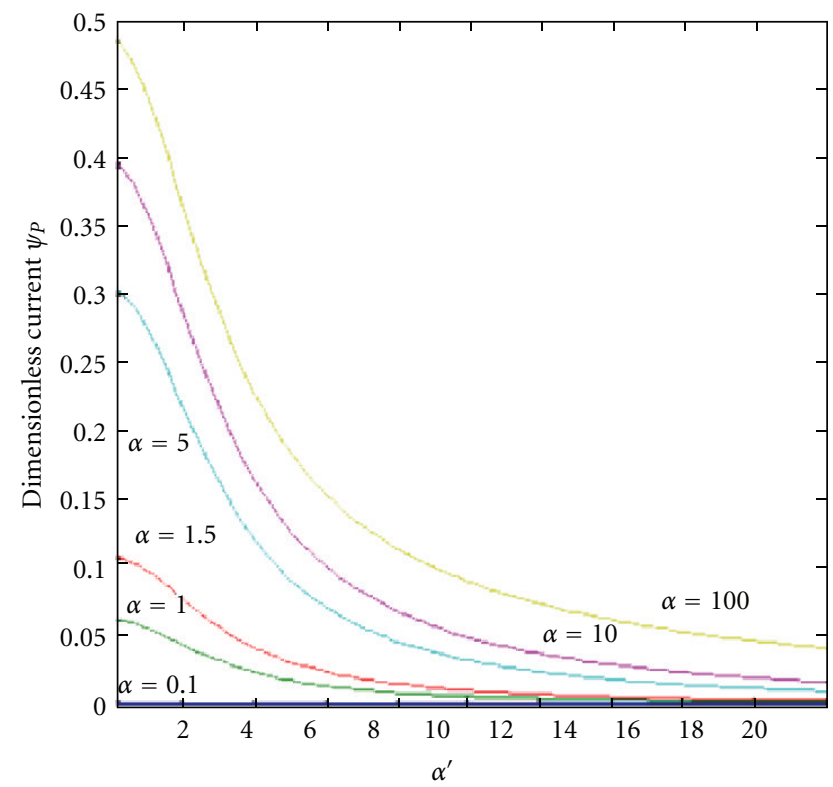

(b)

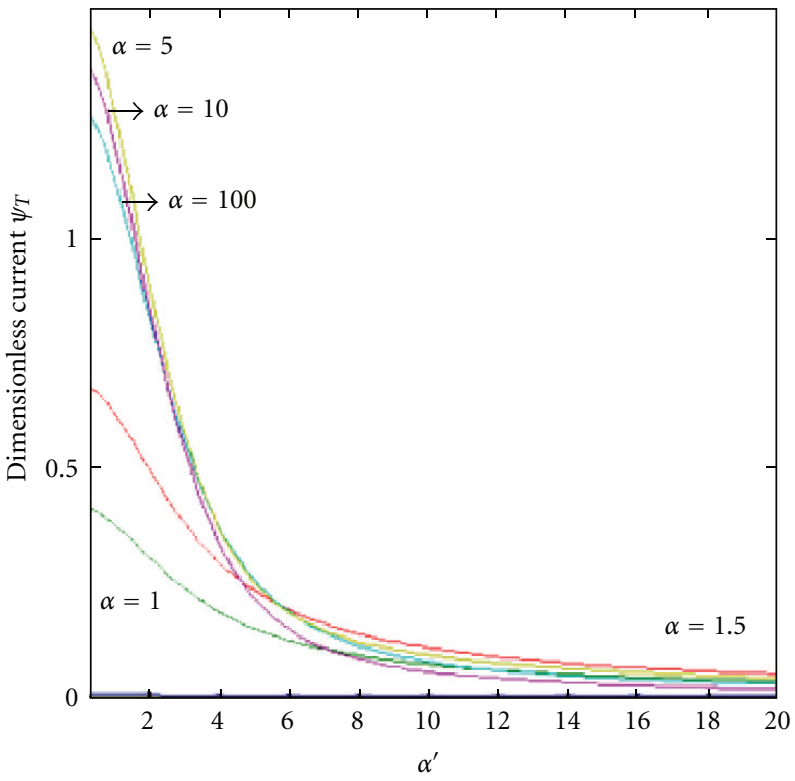

(c)

Figure 6: Profile of the normalized current for first-order kinetics. The current curves were computed for various values of $\alpha, \alpha^{\prime}$, and $M$. The curves are plotted using (18)-(20).

Substituting (A.3) into (A.1) and comparing the coefficients of like powers of $p$ :

$$
\begin{aligned}
& p^{0}: \frac{d^{2} U_{0}}{d X^{2}}-\alpha^{2} U_{0}=0 \\
& p^{1}: \frac{d^{2} U_{1}}{d X^{2}}-\alpha^{2} U_{1}+M U_{0} \frac{d^{2} U_{0}}{d X^{2}}=0 .
\end{aligned}
$$

The boundary conditions for the above equations are

$$
\begin{array}{llll}
\frac{d U_{0}}{d X}=0 & \text { at } X=0, & U_{0}=1, & \text { at } X=1, \\
\frac{d U_{1}}{d X}=0 & \text { at } X=0, & U_{1}=0, & \text { at } X=1 .
\end{array}
$$

Using this boundary conditions the solution of (A.4) becomes as follows:

$$
\begin{aligned}
U_{0}= & \frac{\cosh (\alpha X)}{\cosh (\alpha)} \\
U_{1}= & \frac{M \cosh (\alpha X)(\cosh (2 \alpha)-3)}{6 \cosh ^{3}(\alpha)} \\
& -\frac{M(\cosh (2 \alpha X)-3)}{6 \cosh ^{2}(\alpha)}
\end{aligned}
$$

Adding (A.6) we get (10) in the text 

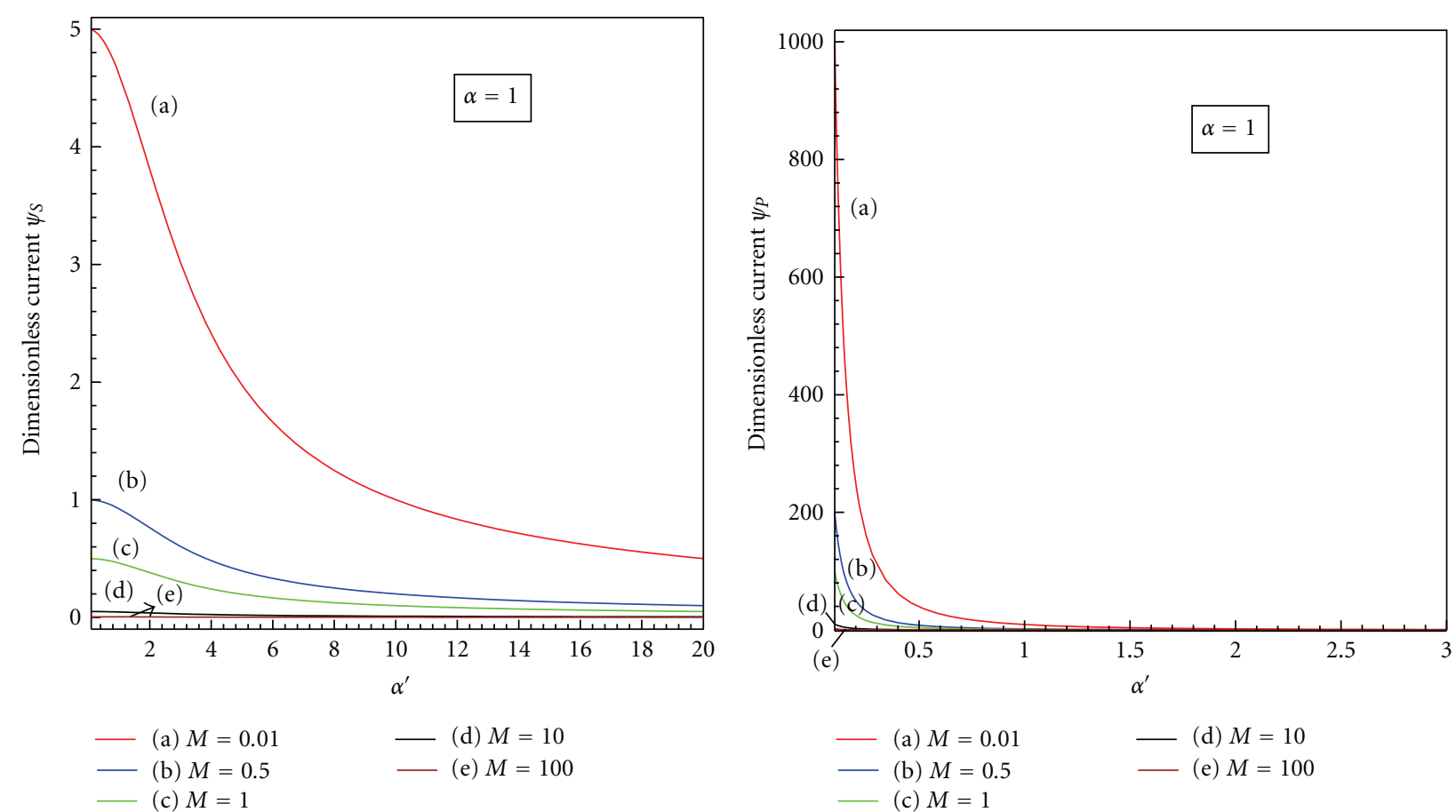

(a)

(b)

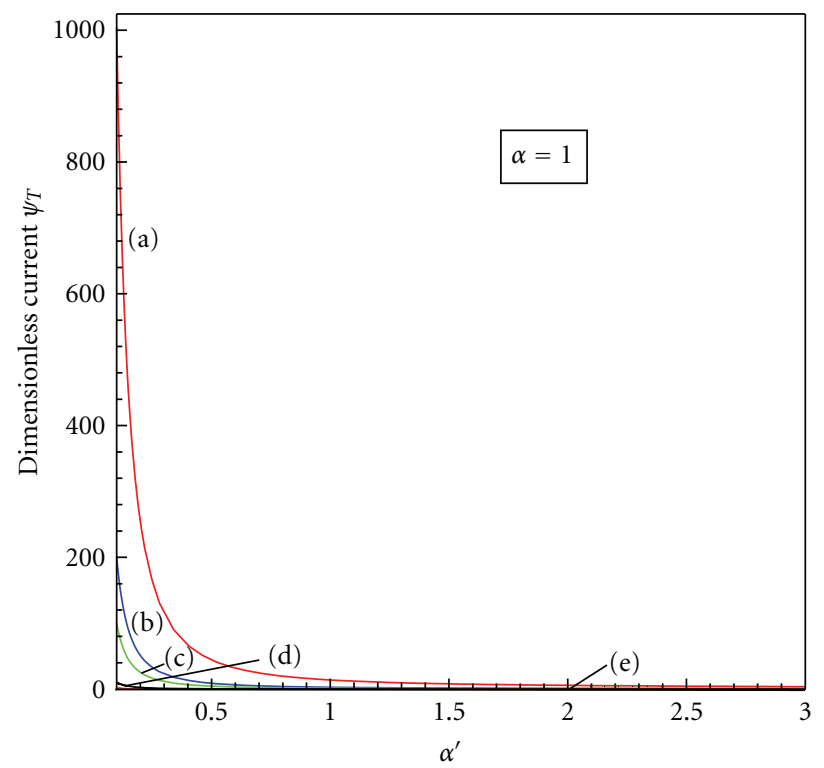
- (a) $M=0.01$
(d) $M=10$
(b) $M=0.5$
(c) $M=1$

(a) $M=0.01$

(b) $M=0.5$

(d) $M=10$

(c) $M=1$

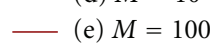

(c)

FIGURE 7: Variation of normalized non-steady-state current response for zero-order kinetics. The current curves were computed for various values of $\alpha, \alpha^{\prime}$ and $M$. The curves are plotted using (24)-(26).

The approximate solution of (A.2) is given by

$$
V=V_{0}+p V_{1}+p^{2} V_{2}+p^{3} V_{3}+\cdots
$$

Substituting (A.3) and (A.2) and arranging the coefficients of like powers of $p$, we have

$$
p^{0}: \frac{d^{2} V_{0}}{d X^{2}}-\alpha^{\prime 2} V_{0}=0,
$$

$$
p^{1}: \frac{d^{2} V_{1}}{d X^{2}}-\alpha^{\prime 2} V_{1}+\frac{\alpha^{2} U_{0}}{M U_{0}+1}=0
$$

The boundary conditions for the above equations are as follows

$$
\begin{array}{ll}
V_{0}=0, & V_{1}=0,
\end{array}
$$


Upon solving (A.7) and (A.8), and using this boundary condition, we get

$$
\begin{gathered}
V_{0}(X)=0, \\
V_{1}(X)=\frac{\alpha^{2}}{\alpha^{\prime 2}(M+1)}\left[1-\frac{e^{\alpha^{\prime} X}+e^{\alpha^{\prime}(1-X)}}{\left(e^{\alpha^{\prime}}+1\right)}\right] .
\end{gathered}
$$

Adding (A.11) we get, (11) in the text.

\section{Acknowledgemnts}

This work was supported by the University Grants Commission (F. No. 39-58/2010(SR)), New Delhi, India and Council of Scientific and Industrial Research (CSIR No.: 01(2442)/10/EMR-II), New Delhi, India. The authors are thankful to Dr. R. Murali, The Principal, The Madura College, Madurai and The Secretary, Madura College Board, Madurai for their encouragement.

\section{References}

[1] H. Silman and E. Katchalski, "Waterinsoluble derivatives of enzymes, antigens and antibodies," Annual Review of Biochemistry, vol. 35, pp. 837-877, 1966.

[2] E. J. Vandamme, "Peptide antibiotic production through immobilized biocatalyst technology," Enzyme and Microbial Technology, vol. 5, no. 6, pp. 403-416, 1983.

[3] B. Schulze and M. G. Wubbolts, "Biocatalysis for industrial production of fine chemicals," Current Opinion in Biotechnology, vol. 10, pp. 609-615, 1999.

[4] L. C. Clark and C. Lyons, "Electrode systems for continuous monitoring in cardiovascular surgery," Annals of the New York Academy of Sciences, vol. 102, pp. 29-45, 1962.

[5] D. H. Campbell, F. L. Luescher, and L. S. Lerman, "Immologic adsorbents. I. Isolation of antibody by means of a celluloseprotein antigen," Proceedings of the National Academy of Sciences, vol. 37, pp. 575-578, 1951.

[6] S. Watanabe, Y. Shimizu, T. Teramatsu, T. Murachi, and T. Hino, "Application of immobilized enzymes for biomaterials used in surgery," Methods in Enzymology, vol. 137, pp. 545-551, 1988.

[7] T. M. S. Chang, Medical Application of Immobilised Enzymes and Proteins, vol. 1-2, Plenum Press, New York, NY, USA, 1977.

[8] M. D. Klein and R. Langer, "Immobilised enzymes in clinical medicines: an emerging approaches to new drug therapies," Trends in Biotechnology, vol. 4, pp. 179-186, 1986.

[9] L. J. Kircka and G. H. G. Thorpe, "Immobilised enzymes in analysis," Trends in Biotechnology, vol. 4, pp. 253-258, 1986.

[10] B. R. Dunlap, Immobilised Chemicals and Affinity Chromatography, Plenum Press, New York, NY, USA, 1974.

[11] G. F. Bickerstaff, "Application of immobilised enzymes to fundamental studies on enzyme structure and function," in Topics in Enzyme and Fermentation Biotechnology, A. Wiseman, Ed., pp. 162-201, Ellis Horwood, Chichester, UK, 1984.

[12] K. Martinek and V. V. Mozhaev, "Immobilization of enzymes: an approach to fundamental studies in biochemistry," Advances in Enzymology and Related Areas of Molecular Biology, vol. 57, pp. 179-249, 1985.
[13] C. Cristallini, L. Lazzeri, M. G. Cascone, G. Polacco, D. Lupinacci, and N. Barbani, "Enzyme-based bioartificial polymeric materials: the $\alpha$-amylase-poly(vinyl alcohol) system," Polymer International, vol. 44, no. 4, pp. 510-516, 1997.

[14] P. J. Worsfold, "Classification and chemical characteristics of immobilized enzymes," Pure and Applied Chemistry, vol. 67, no. 4, pp. 597-600, 1995.

[15] N. C. Foulds and C. R. Lowe, "Enzyme entrapment in electrically conducting polymers. Immobilisation of glucose oxidase in polypyrrole and its application in amperometric glucose sensors," Journal of the Chemical Society, Faraday Transactions 1, vol. 82, no. 4, pp. 1259-1264, 1986.

[16] P. N. Bartlett and R. G. Whitaker, "Electrochemical immobilisation of enzymes. Part II. Glucose oxidase immobilised in poly$N$-methylpyrrole," Journal of Electroanalytical Chemistry, vol. 224, no. 1-2, pp. 37-48, 1987.

[17] D. Bélanger, J. Nadreau, and G. Fortier, "Electrochemistry of the polypyrrole glucose oxidase electrode," Journal of Electroanalytical Chemistry, vol. 274, no. 1-2, pp. 143-155, 1989.

[18] P. Janda and J. Weber, "Quinone-mediated glucose oxidase electrode with the enzyme immobilized in polypyrrole," Journal of Electroanalytical Chemistry, vol. 300, no. 1-2, pp. 119-127, 1991.

[19] M. Marchesiello and E. M. Geniés, "Glucose sensor: polypyrrole-glucose oxidase elecrtode in the presence of p-benzoquinone," Electrochimica Acta, vol. 37, no. 11, pp. 1987-1992, 1992.

[20] Y. Kajiya, H. Sugai, C. Iwakura, and H. Yoneyama, "Glucose sensitivity of polypyrrole films containing immobilized glucose oxidase and hydroquinonesulfonate lons," Analytical Chemistry, vol. 63, no. 1, pp. 49-54, 1991.

[21] P. N. Bartlett, Z. Ah, and V. E. Field, "Electrochemical immobilisation of enzymes," Journal of the Chemical Society, Faraday Transactions, vol. 88, no. 18, p. 2677, 1992.

[22] Y. Kajiya, R. Tsuda, and H. Yoneyama, "Conferment of cholesterol sensitivity on polypyrrole films by immobilization of cholesterol oxidase and ferrocenecarboxylate ions," Journal of Electroanalytical Chemistry, vol. 301, no. 1-2, pp. 155-164, 1991.

[23] Y. Kajiya, H. Matsumoto, and H. Yoneyama, "Glucose sensitivity of poly(pyrrole) films containing immobilized glucose dehydrogenase, nicotinamide adenine dinucleotide, and $\beta$ naphthoquinonesulphonate ions," Journal of Electroanalytical Chemistry, vol. 319, no. 1-2, pp. 185-194, 1991.

[24] N. C. Foulds and C. R. Lowe, "Immobilization of glucose oxidase in ferrocene-modified pyrrole polymers," Analytical Chemistry, vol. 60, no. 22, pp. 2473-2478, 1988.

[25] P. N. Bartlett and R. G. Whitaker, "Electrochemical immobilisation of enzymes: part II. Glucose oxidase immobilised in poly$N$-methylpyrrole," Journal of Electroanalytical Chemistry, vol. 224, no. 1-2, pp. 37-48, 1987.

[26] M. Marchesiello and E. Geniès, "A theoretical model for an amperometric glucose sensor using polypyrrole as the immobilization matrix," Journal of Electroanalytical Chemistry, vol. 358, no. 1-2, pp. 35-48, 1993.

[27] C. Bourdillon, C. Hervagault, and D. Thomas, "Increase in operational stability of immobilized glucose oxidase by the use of an artificial cosubstrate," Biotechnology and Bioengineering, vol. 27, no. 11, pp. 1619-1622, 1985.

[28] H. Naarmann, W.R. Salaneck, D.T. Clark, and E. J. Samuelsen, "Science and applications of conducting polymers," in Proceedings of the 6th Europhysics Industrial Workshop, Adam Hiler, Lofthus, Norway, May 1990. 
[29] E. M. Geniès, M. Marchesiello, and G. Bidan, "Preparation and properties of polypyrrole made in the presence of biological buffers," Electrochimica Acta, vol. 37, no. 6, pp. 1015-1020, 1992.

[30] Q. K. Ghori, M. Ahmed, and A. M. Siddiqui, "Application of homotopy perturbation method to squeezing flow of a newtonian fluid," International Journal of Nonlinear Sciences and Numerical Simulation, vol. 8, no. 2, pp. 179-184, 2007.

[31] T. Öziş and A. Yildirim, "A comparative study of he's homotopy perturbation method for determining frequency-amplitude relation of a nonlinear oscillator with discontinuities," International Journal of Nonlinear Sciences and Numerical Simulation, vol. 8, no. 2, pp. 243-248, 2007.

[32] S. J. Li and Y. X. Liu, "An improved approach to nonlinear dynamical system identification using PID neural networks," International Journal of Nonlinear Sciences and Numerical Simulation, vol. 7, no. 2, pp. 177-182, 2006.

[33] M. M. Mousa and S. F. Ragab, "Application of the homotopy perturbation method to linear and nonlinear schrödinger equations," Z. Naturforsch, vol. 63a, pp. 140-144, 2008.

[34] J. H. He, "Homotopy perturbation technique," Computer Methods in Applied Mechanics and Engineering, vol. 178, no. 3-4, pp. 257-262, 1999.

[35] J. H. He, "Homotopy perturbation method: a new nonlinear analytical technique," Applied Mathematics and Computation, vol. 135, no. 1, pp. 73-79, 2003.

[36] J. H. He, "A simple perturbation approach to Blasius equation," Applied Mathematics and Computation, vol. 140, no. 2-3, pp. 217-222, 2003.

[37] J.H.He, "Homotopy perturbation method for solving boundary value problems," Physics Letters A, vol. 350, no. 1-2, pp. 87-88, 2006.

[38] M. Ghasemi, M. Tavassoli kajani, and E. Babolian, "Numerical solutions of the nonlinear integro-differential equations: wavelet-Galerkin method and homotopy perturbation method," Applied Mathematics and Computation, vol. 188, no. 1, pp. 450-455, 2007.

[39] Z. Odibat and S. Momani, "A reliable treatment of homotopy perturbation method for Klein-Gordon equations," Physics Letters A, vol. 365, no. 5-6, pp. 351-357, 2007. 

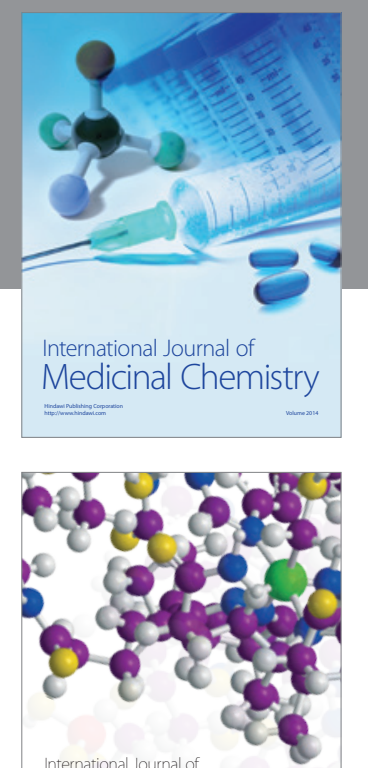

\section{Carbohydrate} Chemistry

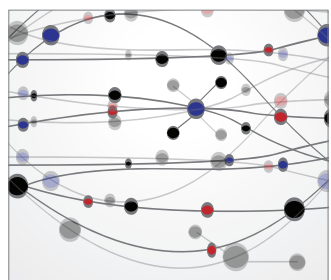

The Scientific World Journal
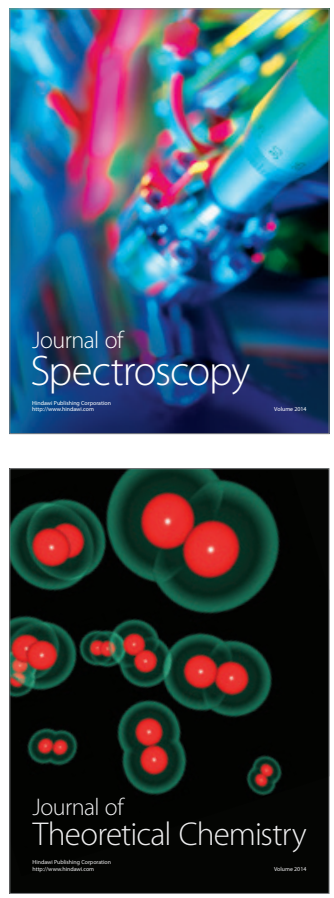
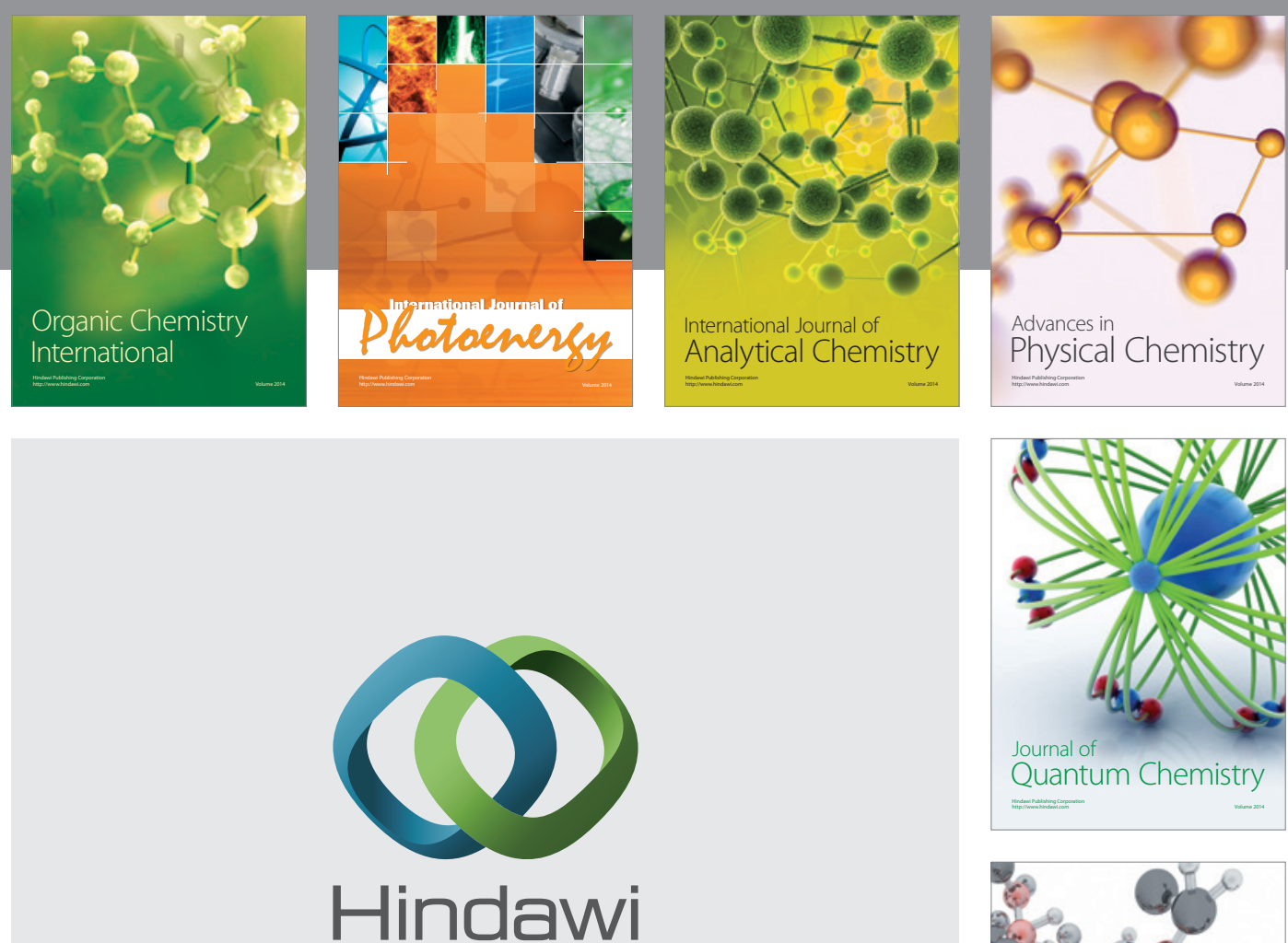

Submit your manuscripts at

http://www.hindawi.com

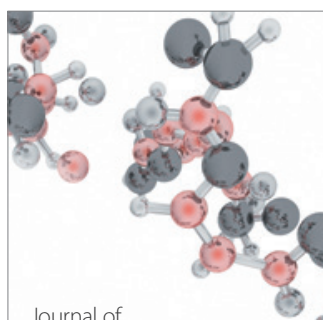

Analytical Methods

in Chemistry

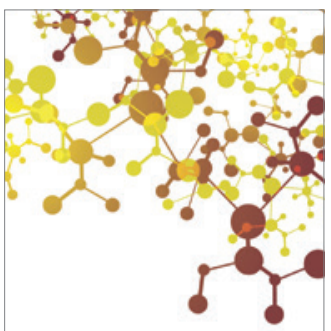

Journal of

Applied Chemistry

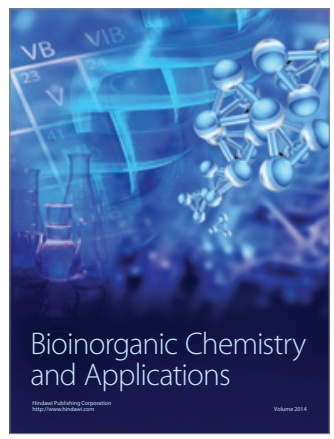

Inorganic Chemistry
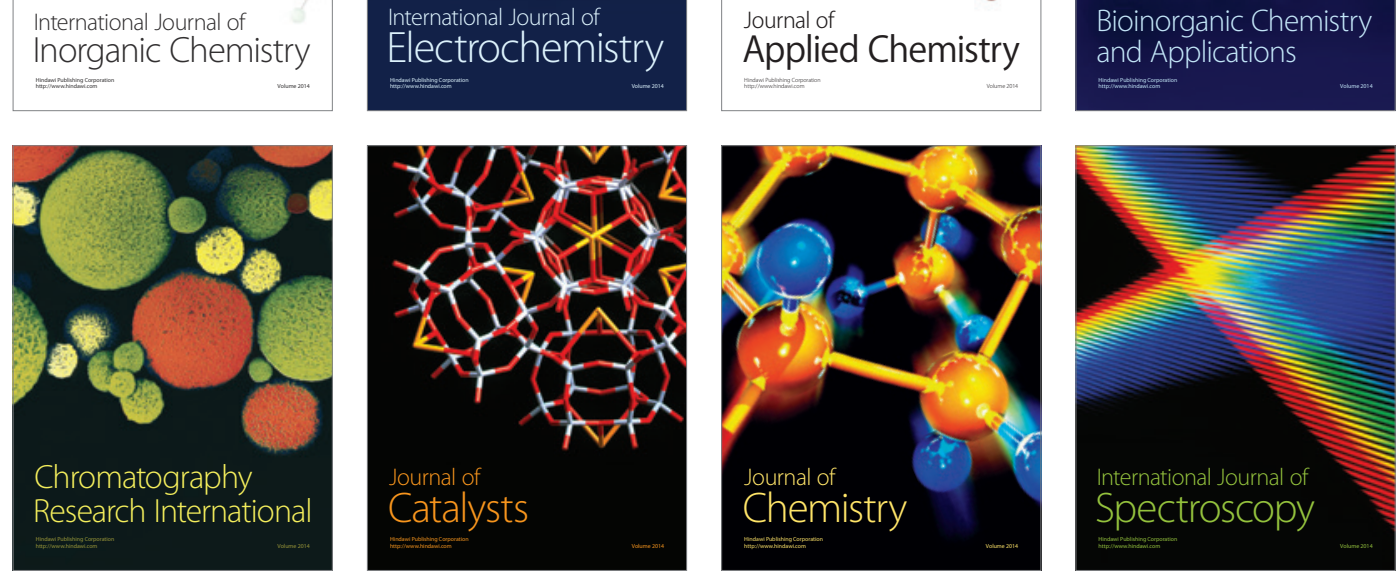